\title{
Ionosphere modelling for Galileo single frequency users: illustration of the combination of the NeQuick model and GNSS data ingestion
}

\author{
B. Bidaine* \\ F.R.S.-FNRS/University of Liège, Geomatics Unit, Allée du 6-Août 17, B-4000 \\ Liège, Belgium \\ R. Warnant \\ Royal Meteorological Institute of Belgium, Avenue Circulaire 3, B-1180 Brussels, \\ Belgium
}

\begin{abstract}
The ionospheric effect remains one of the main factors limiting the accuracy of Global Navigation Satellite Systems (GNSS) including Galileo. For single frequency users, this contribution to the error budget will be mitigated by an algorithm based on the NeQuick global ionospheric model. This quick-run empirical model provides flexible solutions for combining ionospheric information obtained from various sources, from GNSS to ionosondes and topside sounders. Hence it constitutes an interesting simulation tool not only serving Galileo needs for mitigation of the ionospheric effect but also widening the use of new data.

In this study, we perform slant TEC data ingestion - the optimisation procedure underlying the Galileo single frequency ionospheric correction algorithm - into NeQuick for a dozen locations around the world where both an ionosonde and a GPS receiver are installed. These co-located instruments allow us to compare measured and modelled vertical TEC showing for example global statistics or dependence towards latitude. We analyse measurements for the year 2002 (high solar activity level) giving an insight into the situation we could observe when Galileo reaches its Full Operation Capability, during the next solar maximum.

At last we compare Galileo and GPS ionospheric corrections. For Galileo, we end up with an underestimation of $11 \%$ and $4 \%$ depending on the version of NeQuick embedded in the algorithm, as well as a $22 \%$ standard deviation. This means respectively twice, five and 1.5 times better than GPS.
\end{abstract}

Key words: GNSS, Galileo, Ionospheric correction, Single frequency, NeQuick, Data ingestion 


\section{Introduction}

The accuracy of GNSS-based positioning/navigation is influenced by errors induced by the satellite, receiver, and propagation medium (HofmannWellenhof et al., 2008). The first two categories include for instance the biases due to the satellite and receiver clocks. The last category comprises influences on the propagation of navigation signals within the Earth atmosphere. Two cases are usually distinguished corresponding to two parts of the atmosphere: the neutral part is referred to as the troposphere and the region containing free electrons the ionosphere.

The ionosphere is known to induce scintillations and time delays among other effects (Arbesser-Rastburg and Jakowski, 2007). The latter constitutes the major error source for ranging applications. For code measurements, it leads to a pseudorange error $[m]$

$$
I_{g}=\frac{40.3}{f^{2}} \int_{\text {sat. }}^{r e c .} N_{e} d s=\frac{40.3}{f^{2}} s T E C
$$

where $f$ denotes the signal frequency $[H z], N e$ the electron concentration [electrons $\left.\mathrm{m}^{-3}\right]$ and $s T E C$ the slant total electron content $\left[\mathrm{el.m} \mathrm{m}^{-2}\right]$. As every ionospheric parameter, the value of TEC depends on different factors such as location, time of day, season, solar or geomagnetic activity. It is more generally measured in TEC units $\left[\right.$ TECu $\left.=10^{16} \mathrm{el} . \mathrm{m}^{-2}\right]$.

Various strategies exist to mitigate the ionospheric effects on GNSS (Warnant et al., 2009). They depend on the application, more or less precise, and on the availability of one or more signal frequencies. For multi-frequency devices, the ionospheric delay can be mitigated by means of specific combinations of measurements, taking advantage of the dispersive property of the ionosphere. On the contrary, single frequency navigation - our field of investigation - requires an ionospheric model, for TEC in particular. For the Global Positioning System (GPS), the Single Frequency Ionospheric Correction Algorithm (SF ICA) is based on the Bent model (Klobuchar, 1987). It uses eight broadcast coefficients from the navigation message to compute vertical TEC ( $v T E C$ ). Assuming a thin shell ionosphere, sTEC is then computed by means of an appropriate mapping function and converted to time delay. This technique is supposed to provide a $50 \%$ root-mean-square (RMS) correction of the ionospheric time delay.

\footnotetext{
* Corresponding author

Email addresses: B.Bidaine@ulg.ac.be (B. Bidaine), R. Warnant@oma. be (R. Warnant).
}

Bidaine et Warnant - doi:10.1016/j.asr.2010.09.001 
In the case of Galileo, the NeQuick model will be used together with three broadcast coefficients that will permit to compute the electron density along the satellite-to-receiver ray-path. Subsequently the electron density values will be integrated to obtain the corresponding sTEC (Arbesser-Rastburg, 2006). According to its specification, this method should exhibit a maximum residual error of $20 T E C u$ or $30 \%$ of the actual sTEC, whichever is larger, for satellites above $10^{\circ}$ elevation and nominal ionospheric conditions. Orus et al. (2007a) conclude that NeQuick meets this specification. Considering a high solar activity year (2000), they state an error of $30 \%$ for the latest version of the model and improvements at almost all latitudes by comparison to the previous version. They also show a large decrease of the global bias (between 60 and 80\%) down to below 1 TECu for NeQuick 2 and the whole year 2000.

In the present study, we use co-located GPS and ionosonde measurements during a high solar activity year to illustrate the different elements exploited within Galileo SF ICA. We first focus the analysis on the optimisation procedure, called data ingestion, constituting the core of the algorithm. We compare it with another use of the model based on ionosonde measurements to infer how it can cope with NeQuick possible inaccuracies. Then we extend the analysis towards Galileo and GPS SF ICA.

Data ingestion and assimilation techniques are usually associated but not often clearly distinguished. Both of them combine an underlying ionospheric model and actual measurements to estimate and predict ionospheric characteristics. However data assimilation formally consists in merging observed information from one or more sources into a first-principles physics model (Wilson et al., 2008). Practically it depends on three choices: the underlying model (which is sometimes empirical), a state representation (e.g. spherical harmonics) and an estimation strategy (e.g. Kalman filter). On the other hand data ingestion intend to drive an empirical model towards one specific data set (Nava et al., 2006). To this extent it computes "effective" parameters associated to the model and the data from single-criterion optimisation.

\section{Tools and method}

\subsection{NeQuick model}

NeQuick belongs to the "DGR family" of ionospheric models known as "profilers". They indeed fit analytical functions on a set of anchor points, namely the $E, F_{1}$ and $F_{2}$ layer peaks, to represent these principal ionospheric layers and compute the electron density profile. NeQuick is the simplest one and was adopted by the ITU-R recommendation for TEC modelling. The NeQuick

Bidaine et Warnant - doi:10.1016/j.asr.2010.09.001 
model is divided into two regions (Radicella and Leitinger, 2001): the bottomside, up to the $F_{2}$-layer peak, consists of a sum of five semi-Epstein layers and the topside, above the $F_{2}$-layer peak, described by means of a single sixth semiEpstein layer with a height-dependent thickness parameter. The parameters of the Epstein layers are computed on the basis of the ionosonde parameters, $f_{o} E, f_{o} F_{1}, f_{o} F_{2}$ and $M(3000) F_{2}$. To obtain these critical frequencies and transmission factor, models can be used such as the CCIR maps for the $F_{2}$ characteristics described in ITU-R Recommendation P.1239. A monthly median situation is then represented. However an advantage of NeQuick consists in its ability to easily accommodate measured values for these parameters(Bidaine and Warnant, 2010).

On the basis of position, time and solar activity index (solar flux or sunspot number) provided as input, the model returns the corresponding electron density. Its first version, referred to either as version 1 or ITU-R, constitutes the current baseline for Galileo. Its FORTRAN 77 code is downloadable from the Internet ${ }^{1}$ within a package including numerical integration subroutines allowing to compute $v T E C$ and $s T E C$.

In the recent years, a second version of NeQuick has been designed (Nava et al., 2008) and is available from the model designers. The main evolution concerns the topside representation. Topside soundings data were indeed processed to modify the formulation of the shape parameter $k$ involved in the topside thickness parameter calculation (Coïsson et al., 2006). It was previously computed on the basis of two formulas, one for months between April and September and the other for the rest of the year, which are replaced by a single one in NeQuick 2.

\subsection{Data ingestion}

Ionospheric models such as NeQuick often use solar activity indices as standard input. These indices are based on solar observation and do not necessarily account perfectly for the solar activity in EUV radiations inducing the ionisation in the Earth atmosphere. On the other hand, models involve mismodellings related to simplified representations of the various ionospheric drivers including solar activity. Hence different "effective" indices have been developed from the combination of ionospheric models and experimental data. They allow to drive a model towards measured values by adapting it to a specific data set, a reconstruction technique usually referred to as data ingestion. These indices are then strictly related to a model/data set combination and should therefore not be considered as better proxies of the solar activity.

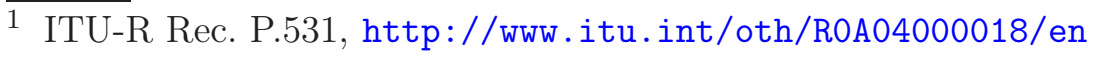

Bidaine et Warnant - doi:10.1016/j.asr.2010.09.001 
NeQuick has often been used in this framework in combination with TEC data (Nava et al., 2006; Bidaine and Warnant, 2008). At a given time and for a given ray path, the TEC value obtained from the integration of NeQuick electron density profile depends monotonically on its solar flux input. The latter is then usually called effective ionisation level $A z$ and is computed by minimising the mismodelling between the model and a subset of TEC measurements. This mismodelling is defined as the Root Mean Square (RMS) difference between modelled and measured TEC

$$
R M S=\sqrt{\left\langle\left(T E C_{\text {mod }}(A z)-T E C_{\text {meas }}\right)^{2}\right\rangle}
$$

where \langle\rangle denotes averaging the available differences within a given period. For a given station, $A z$ can then be inferred from $s T E C$ epoch by epoch or for longer time frames.

\subsection{Ionospheric correction algorithms}

The Galileo SF ICA will rely on daily ingestion of $s T E C$ data collected within the Ground Mission Segment (Hofmann-Wellenhof et al., 2008). Daily effective parameters will indeed be computed at each Galileo Sensor Station (GSS) in various number for the successive Galileo phases. The current experimental mission GIOVE involves 13 stations while the In-Orbit Validation (IOV) phase planned for 2011 will include 18 GSS and the Full Operation Capability (FOC) around 40. For our study, we chose to simulate the IOV network by means of IGS (Dow et al., 2009) and EUREF (Bruyninx et al., 2009) stations (cf. Fig. 1).

To obtain the three coefficients broadcast in the navigation message, the $A z$ values will then be merged through a parabolic adjustment along the modified dip latitude $\mu$ (modip). This parameter linked to the geomagnetic field reveals particularly appropriate for modelling purposes as it combines the geomagnetic dip $I\left[^{\circ}\right]$ and the geographic latitude $\phi\left[^{\circ}\right]$ (Rawer, 1963).

$$
\tan \mu=\frac{I}{\sqrt{\cos \phi}}
$$

At last the user computes the solar activity input of NeQuick by means of the broadcast coefficients $a_{0}, a_{1}$ and $a_{2}$ generated the previous day :

$$
A z=a_{0}+a_{1} \mu+a_{2} \mu^{2} .
$$

By comparison, the GPS SF ICA is very different. This algorithm by Klobuchar (1987) is based on the Bent model and includes many geomet-

Bidaine et Warnant - doi:10.1016/j.asr.2010.09.001 


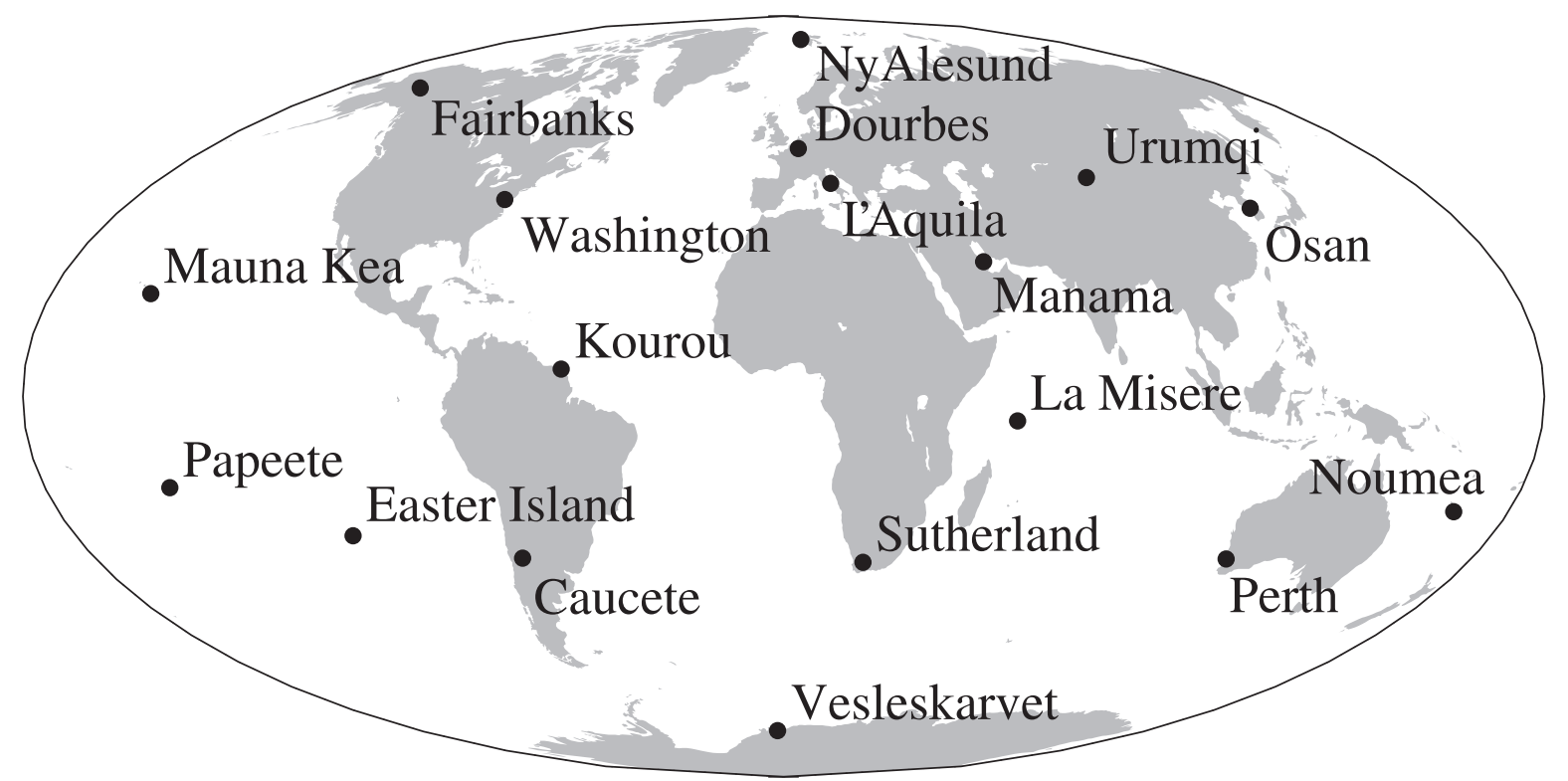

Fig. 1. Simulated stations of Galileo IOV phase.

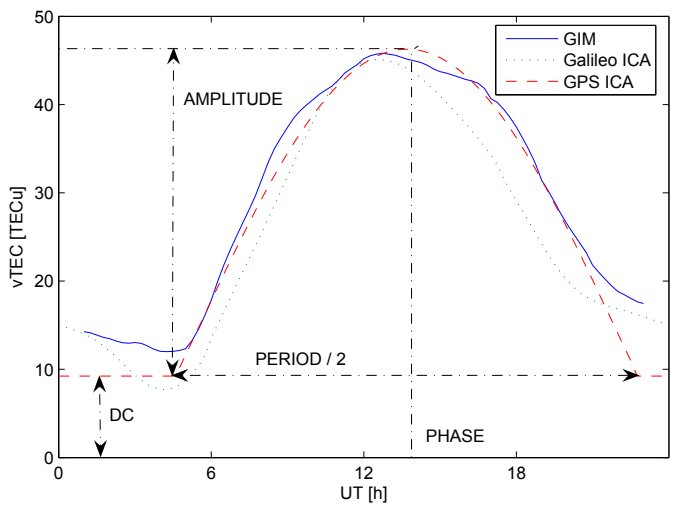

Fig. 2. Daily $v T E C$ profile at Dourbes on September $24^{\text {th }}, 2002$.

ric approximations aiming at reducing user computational requirements. It is primarily intended to provide a $v T E C$ daily profile consisting in a cosine representation during the day and a constant (DC) during night (cf. Fig. 2). The amplitude and the period of the cosine term are obtained each thanks to four broadcast coefficients defining a third order polynomial of the magnetic latitude. The phase of the maximum is fixed at 14:00 local time. The vertical time delay actually computed in this manner is then converted to slant by means of a dedicated mapping function. 


\subsection{Data sets}

In this study, we use three kinds of ionospheric data: ionosonde parameters, $s T E C$ and $v T E C$. For the first, we consider manually validated measurements mainly obtained by ionosondes (Altadill et al., 2009) ${ }^{2}$ and, for the others, GPS-derived data calibrated by means of Global Ionospheric Maps (GIM) (Hernández-Pajares et al., 2009) ${ }^{3}$. As explained in Bidaine and Warnant (2010), the maps provide $s T E C$ values to estimate the ambiguities of the phase geometry-free combination (Orus et al., 2007b). Finally, a subset of $s T E C$ values corresponding to high elevation angles multiplied by the appropriate mapping function are averaged every 15 min to obtain $v T E C$ at stations where ionosonde data are available (Warnant and Pottiaux, 2000).

For the sake of consistency and to enable the comparison described in next subsection, we select 12 locations with co-located ionosonde - DGS when digisonde (Galkin et al., 2006) - and GPS station belonging to IGS, EUREF and CORS (Snay and Soler, 2008) networks (cf. Fig. 3 and Tab. 1). We also focus on a high solar activity period (year 2002).

We give the availability levels of each kind of data and for the combined use of ionosonde parameters and $v T E C$ in Fig. 4. We count maximum 1,051,200 GPS sTEC measurements (one every $30 \mathrm{~s}$ corresponding to the standard sampling rate of GPS observations), 35,040 GPS $v T E C$ values (one every quarter) and 8760 sets of ionosonde parameters (soundings every hour). We explain partially the lower availabilities

- for ionosonde parameters, because no data is available for some months (Tromso: January to April; El Arenosillo: August and September; Townsville and Hobart: November and December; Dourbes and Boulder: January; Point Arguello: July)

- and for $v T E C$, because the odd-hour IONEX format for the GIM leads to a systematic gap between 23 and $1 \mathrm{UT}^{4}$ and because less $s T E C$ data are available at high elevation angles for high-latitude stations (Tromso and Sodankyla).

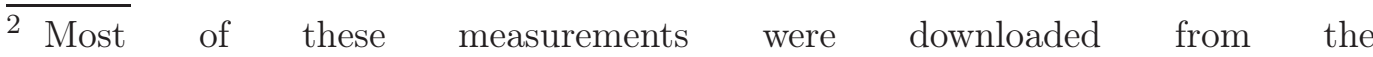
World Data Center for Solar-Terrestrial Physics at Chilton, UK (http://www.ukssdc.ac.uk/wdcc1/data_menu.html).

3 The data set used was computed at ESA using UPC GIMs.

4 On the one hand, GIM are provided in daily files containing maps every two hours from 1 to 23 UT until November 2nd, 2002. On the other hand, two consecutive maps of a given day are used to compute TEC values at a given location and time. Hence no $v T E C$ data is available for periods outside any 2-hour interval between two maps ie before 1 and after 23 UT.

Bidaine et Warnant - doi:10.1016/j.asr.2010.09.001 

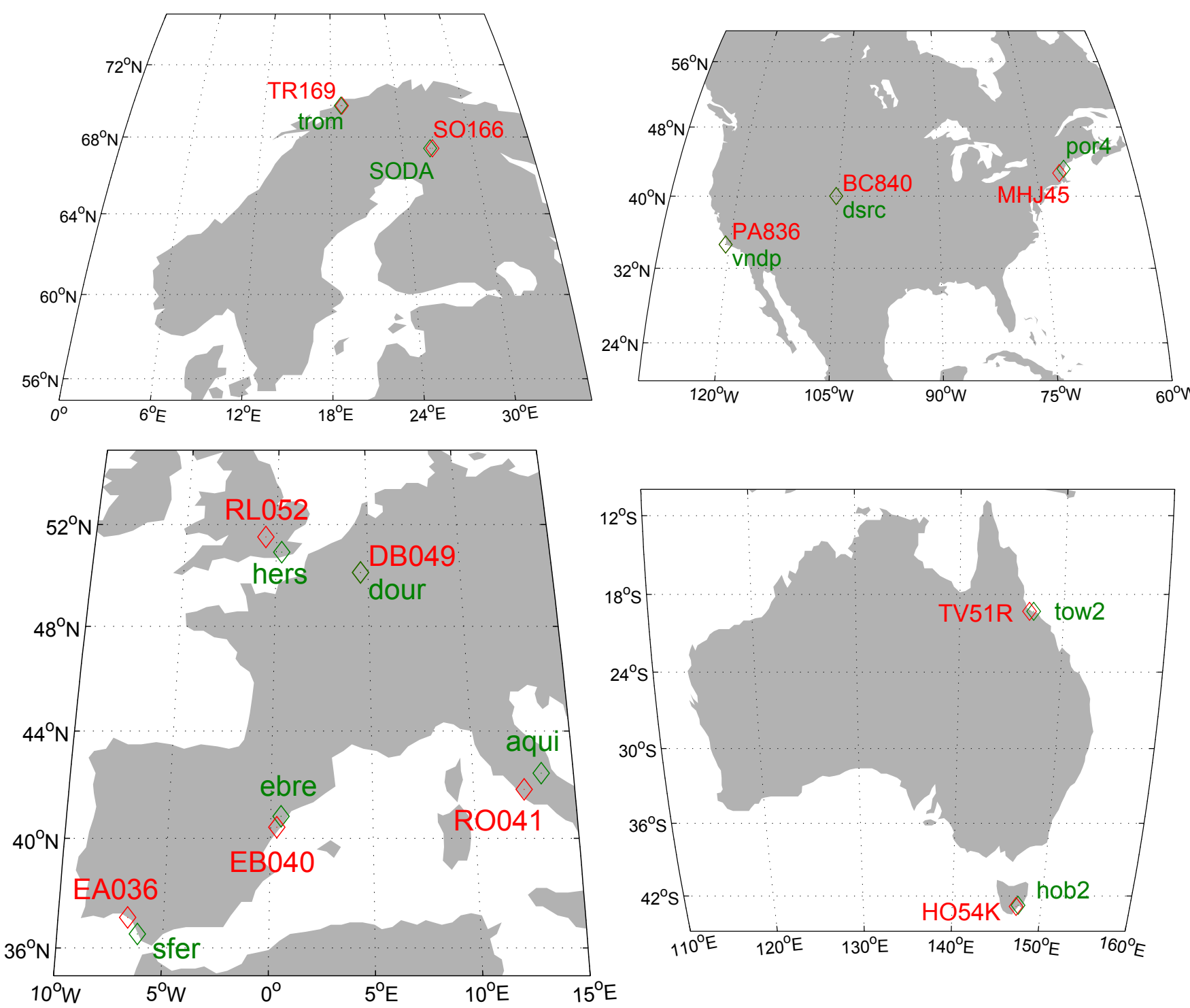

Fig. 3. Co-located ionosondes and GPS stations (top left: high-latitude Europe; bottom left: mid-latitude Europe; top right; North America; bottom right: Australia).

\subsection{Analysis method}

The first step of our analysis consists in uncoupling NeQuick formulation from its underlying data. As explained in Bidaine and Warnant (2010), we use ionosonde parameters (measured values of $f_{o} F_{2}$ and $M(3000) F_{2}$ ) instead of the CCIR maps to obtain a daily representation of the ionosphere in place of the standard monthly median electron density.

Our following and main focus involves a data ingestion scheme similar to the one which will be run at each GSS. We generate daily $A z$ values using the Brent optimisation method (Brent, 1973) with all available satellite-to-receiver ray 
Table 1

Stations identification.

\begin{tabular}{lccccccc}
\hline Location & Ionosonde & Type & Lat. $\left[{ }^{\circ} \mathrm{N}\right]$ & Long. $\left[{ }^{\circ} \mathrm{E}\right]$ & GPS station & Network & $\begin{array}{c}\text { Distance from } \\
\text { ionosonde }[\mathrm{km}]\end{array}$ \\
\hline Tromso & TR169 & DGS & 69.6 & 19.2 & trom & IGS & 16 \\
Sodankyla & SO166 & & 67.4 & 26.6 & soda & EUREF & 9 \\
\hline Chilton & RL052 & DGS & 51.5 & -0.6 & hers & IGS & 91 \\
Dourbes & DB049 & DGS & 50.1 & 4.6 & dour & EUREF & 0 \\
Rome & RO041 & & 41.9 & 12.5 & aqui & EUREF & 93 \\
Roquetes & EB040 & DGS & 40.8 & 0.5 & ebre & IGS & 0 \\
El Arenosillo & EA036 & DGS & 37.1 & -6.7 & sfer & IGS & 80 \\
\hline Millstone Hill & MHJ45 & DGS & 42.6 & -71.5 & por4 & CORS & 86 \\
Boulder & BC840 & DGS & 40.0 & -105.3 & dsrc & CORS & 0 \\
Point Arguello & PA836 & DGS & 34.8 & -120.5 & vndp & IGS & 24 \\
\hline Townsville & TV51R & & -19.6 & 146.9 & tow2 & IGS & 40 \\
Hobart & HO54K & & -42.9 & 147.3 & hob2 & IGS & 14 \\
\hline
\end{tabular}

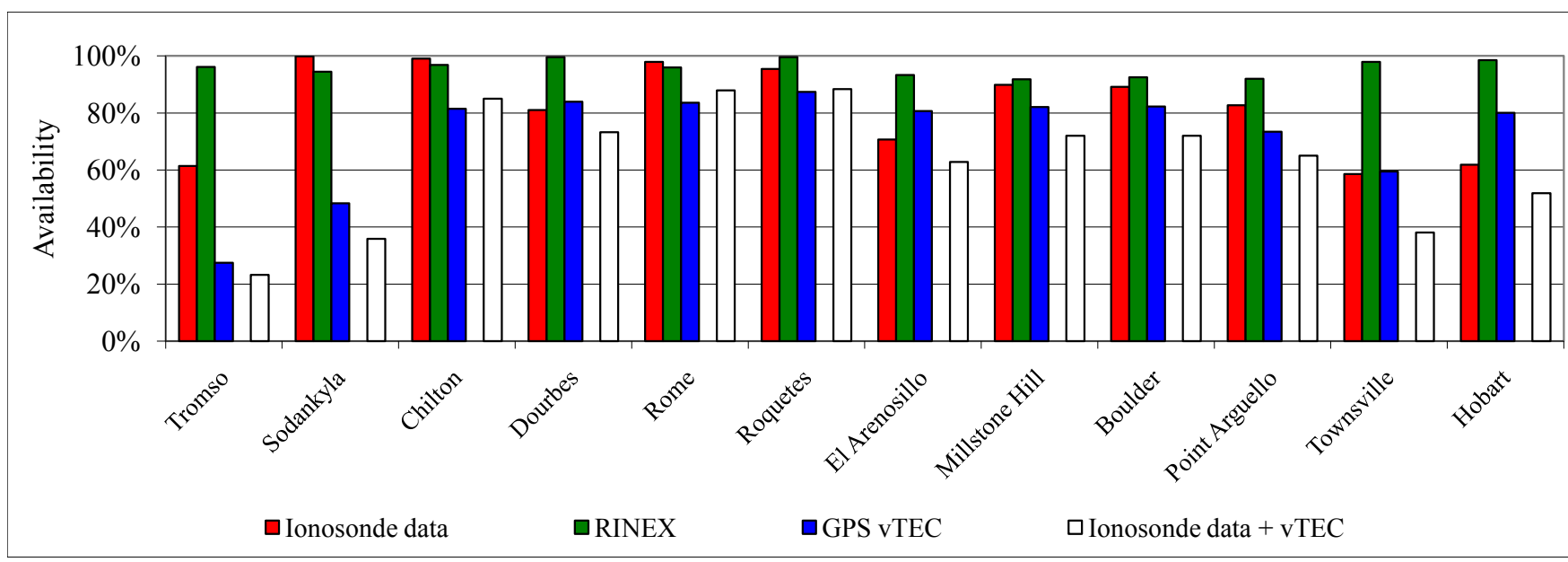

Fig. 4. Data availability.

paths ${ }^{5}$. This allows us to observe how data ingestion can cope with NeQuick intrinsic residual errors. Investigating next the use of the previous day $A z$ will bring us even closer to the Galileo SF ICA. Hence we will quantify the impact of this pragmatic option.

Finally we consider Galileo and GPS SF ICA. It is worth noting that we simulated Galileo broadcast coefficients by means of $s T E C$ obtained from

$\overline{5}$ To limit computation time, we actually used a 30-minute sampling rate.

Bidaine et Warnant - doi:10.1016/j.asr.2010.09.001 
UPC GIMs at the stations of the simulated IOV ground segment (cf. Fig. 1).

To compare the results of these different techniques, we analyse different statistics of $v T E C$ (mean, standard deviation of the difference between measured and modelled values $\sigma_{\triangle T E C}$ or relative standard deviation $\sigma_{\triangle T E C \text {, Relative }}$; cf. eqs. 5 to 7 ) and different time frames (yearly or monthly).

$$
\begin{aligned}
& \overline{\Delta T E C}=\left\langle T E C_{\text {meas }}-T E C_{\text {mod }}\right\rangle \\
& \sigma_{\Delta T E C}=\sqrt{\left\langle\left(T E C_{\text {meas }}-T E C_{\text {mod }}-\overline{\Delta T E C}\right)^{2}\right\rangle} \\
& \sigma_{\Delta T E C, \text { Relative }}=\frac{\sigma_{\Delta T E C}}{\left\langle T E C_{\text {meas }}\right\rangle}
\end{aligned}
$$

For computing yearly statistics, we also group the stations in four regions (cf. Fig. 3) as long as the features of the ionosphere can be considered homogeneous within these regions.

\section{Analysis}

\subsection{Ionosonde parameters constrain}

Constraining NeQuick with ionosonde parameters allows us to investigate the intrinsic behaviour of the model. The data ingestion scheme will indeed drive this initial situation towards measured TEC. In this context, we first examine yearly statistics of $v T E C$. To obtain consistent statistics, we do not consider the months January to April for Sodankyla as ionosonde parameters are not available for Tromso in this period. The same statement applies to the Australian stations for November and December.

Fig. 5 shows the influence of latitude: lower mean TEC values are observed at high latitudes (21 TECu for high-latitude Europe by comparison to 33 for mid-latitude Europe, 30 for North America and 31 for Australia). We also state an average underestimation of about $25 \%$ of both versions of the model, which evolves differently between NeQuick 1 and NeQuick 2 for the different regions. It is increasing for mid-latitude Europe (by about 19\%) and North America (by about 7\%) and apparently decreasing for high-latitude Europe (by about 4\%) and Australia (by about 15\%). However we must not forget that several months of data are not included in the statistics for the last two regions. Hence the following discussion on monthly statistics will help us to clarify the situation.

Bidaine et Warnant - doi:10.1016/j.asr.2010.09.001 10 

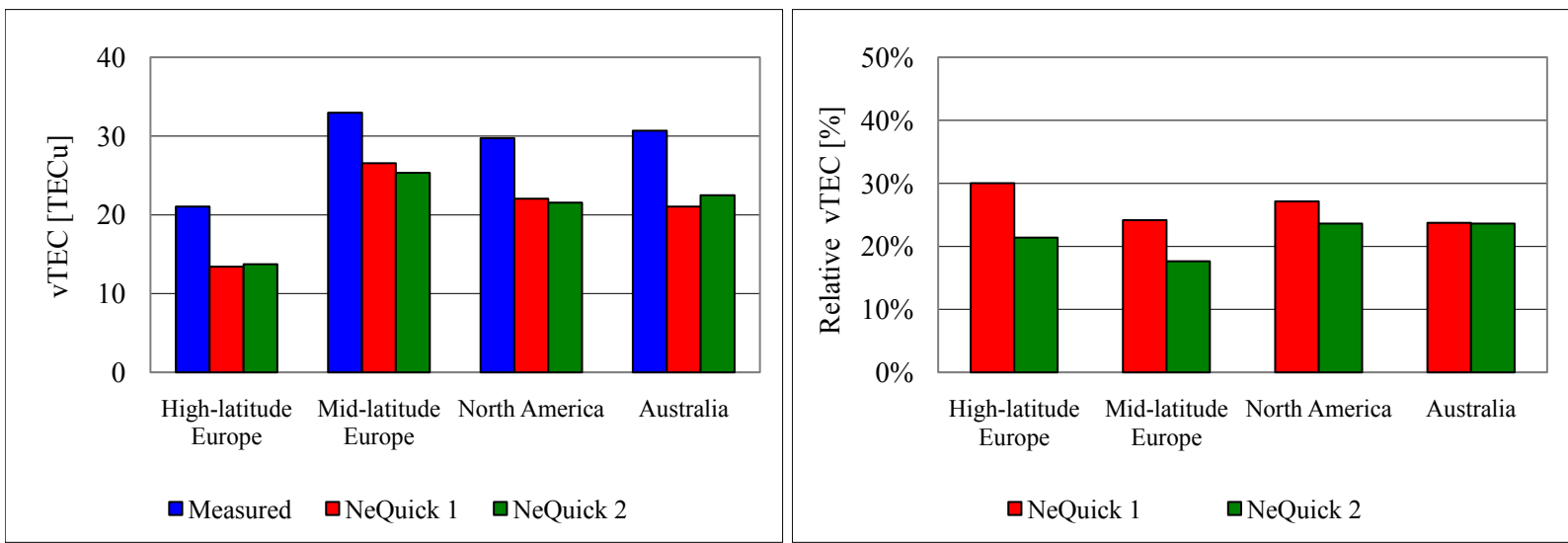

Fig. 5. Yearly $v T E C$ mean (left) and relative standard deviation (right) corresponding to ionosonde parameters constrain.

The observed underestimation has to be interpreted carefully regarding the GPS TEC reconstruction technique. As outlined by previous studies (Ciraolo et al., 2007; Prieto-Cerdeira et al., 2006; Orus et al., 2007a; Bidaine and Warnant, 2009), the latter may indeed be affected by discrepancies of several $T E C u$ at least comparing it with other techniques. The levelling procedure seems here to lead to important consequences, including on the interpretation of the detected bias of the model, a part of which might have to be attributed to the measurements.

The right panel of Fig. 5 presents the relative standard deviation which amounts about $24 \%$. Its reduction by about $17 \%$ for NeQuick 2 indicates an improvement from the second version of the model. In particular its decrease reaches about 28\% in Europe, $13 \%$ in North America and is very small in Australia where the result must be interpreted considering the missing data for this region.

To refine our analysis, we investigate monthly statistics an example of which is given in Fig. 6 for Millstone Hill. We find the same underestimation than for yearly statistics apart from November and December for NeQuick 1. Regarding the evolution from one version of the model to the other, we note decreasing biases for April to September, increasing underestimation for the rest of the year and decreasing standard deviations for the whole year apart from January. However the improvement suggested by the lower standard deviations appears rather small for the months April to September. The latter 6 -month period seems then distinct from the other in terms of bias as well as standard deviation.

As described in Section 2.1, the major modification between both NeQuick versions is related to the topside. The two formulas (one for April to September and the other for October to March) for the shape parameter k in NeQuick 1 were replaced by a single one in NeQuick 2 . Hence the two identified peri- 

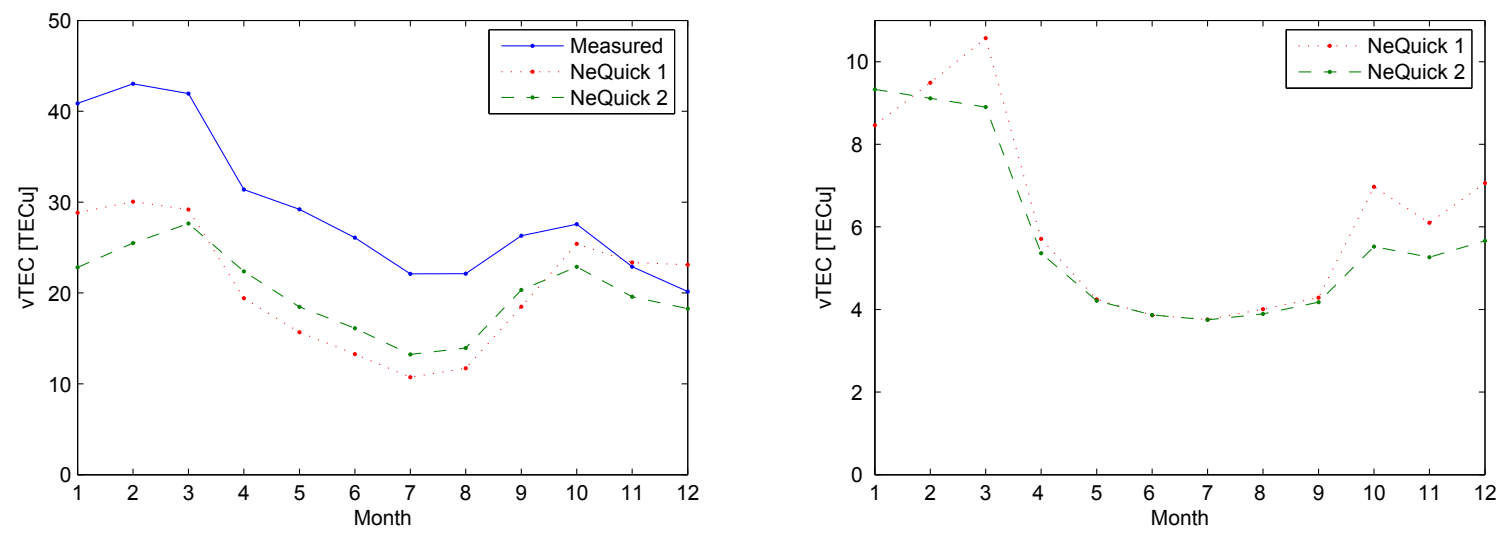

Fig. 6. Monthly $v T E C$ mean (left) and standard deviation (right) for Millstone Hill.

ods correspond to the $\mathrm{k}$ formulas in NeQuick 1, which enables to get different statistics for both of them. In the illustrated example, the bias decreases for the first period and the standard deviation for the second, leading to an homogenisation of NeQuick performances all along the year. An expected significant bias increase from November to March would then have influenced yearly statistics for high-latitude Europe and Australia in a consistent way with the other regions. A similar reasoning can be followed for November and December in the Australian region regarding the standard deviation.

Finally considering the overall scheme for this use of the model, we conclude that it provides the best results in mid-latitude Europe and that it works the worst in high-latitude Europe.

\subsection{Slant TEC data ingestion}

For this second part of the study, we do not need ionosonde parameters anymore. Hence the yearly statistics in which we are interested are not affected by missing months anymore. To perform $s T E C$ data ingestion, we generate daily $A z$ values which minimise the RMS difference between modelled and measured $s T E C$ data of each entire day at a given station. Then we run the model with these parameters to compute $v T E C$ to be compared with GPS $v T E C$.

We still observe an underestimation for both versions of NeQuick (cf. Fig. 7 ) but it drops to about $8 \%$ by comparison with the use in combination with ionosonde measurements. Unlike for that use, it is decreasing between NeQuick 1 and NeQuick 2 for all regions (about 5\% for high-latitude Europe, 27\% for mid-latitude Europe, $19 \%$ North America and $49 \%$ for Australia). Thus the bias is absorbed thanks to data ingestion even better with NeQuick 2. 

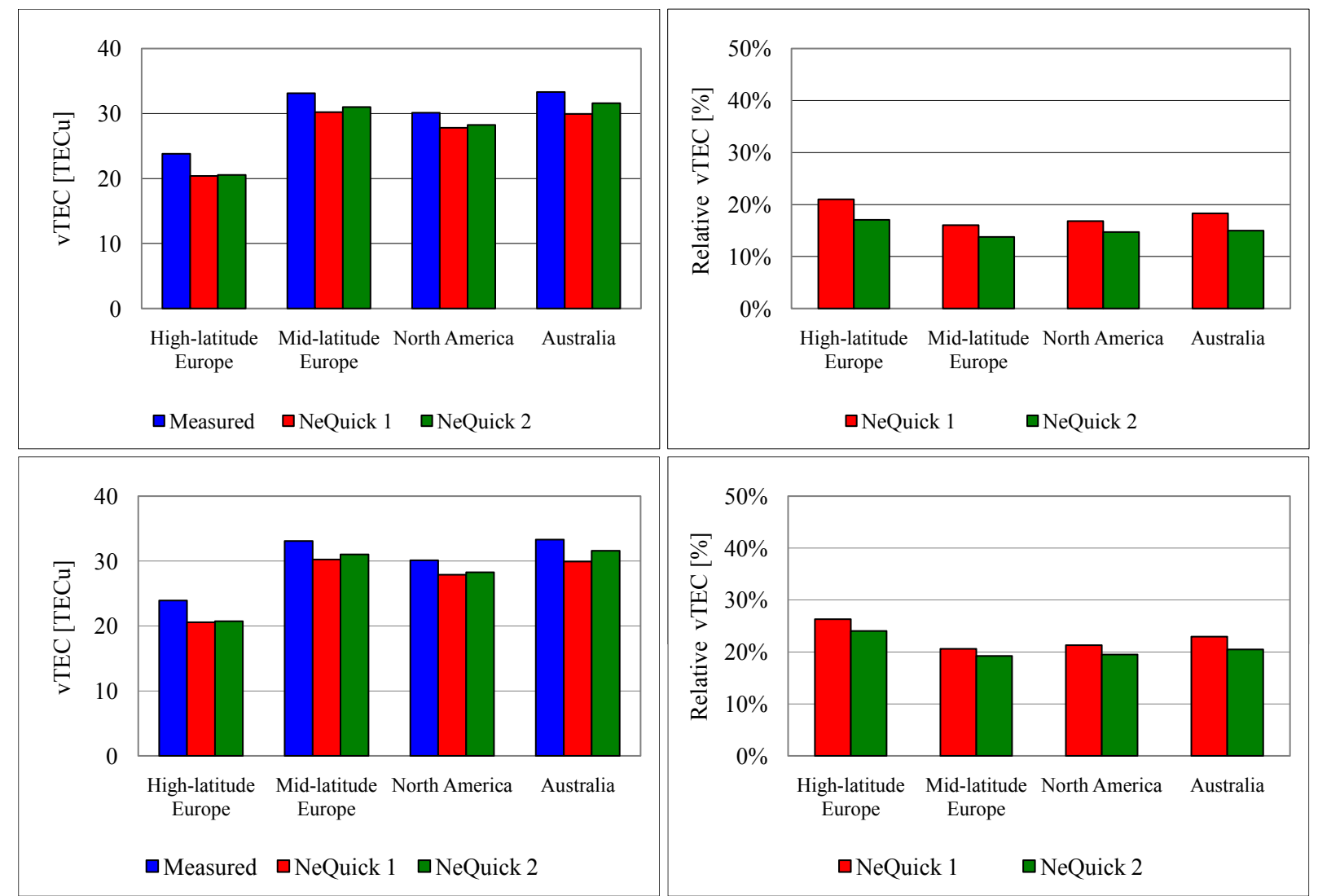

Fig. 7. Yearly $v T E C$ mean (left) and relative standard deviation (right) corresponding to $s T E C$ data ingestion using current day (top) and previous day (bottom) Az.

In terms of relative standard deviation, the average is much smaller than in the first part of the analysis (about 16\%). The modifications of the second version of the model reduce the standard deviation by about $15 \%$. Therefore both indicators show better performances for NeQuick 2 and how $s T E C$ data ingestion can handle the model residual errors. They also confirm the best case for mid-latitude Europe and the worst for high-latitude Europe.

Another interesting characterisation of $s T E C$ data ingestion results concerns the effective ionisation level $A z$. This parameter plays the role of the solar activity input of the NeQuick model. The use of the monthly smoothed sunspot number $R_{12}$, the adequate index to accommodate CCIR maps and provide monthly median output, or various solar flux averages leads to biases. In our case, the absorption of the corresponding underestimation obtained when constraining NeQuick with ionosonde parameters induces $A z$ values (cf. Fig. 8) larger than the converted $R_{12}$ (yearly mean $\simeq 147\left[10^{-22} \mathrm{Wm}^{-2} \mathrm{~Hz}^{-1}\right]$ ) or even than solar flux (yearly mean of daily flux $\simeq 179.5\left[10^{-22} \mathrm{Wm}^{-2} \mathrm{~Hz}^{-1}\right]$ ).

Even if the bias is larger for NeQuick 2, lower values of $A z$ are computed thanks to its better topside formulation. The $v T E C$ values obtained with 


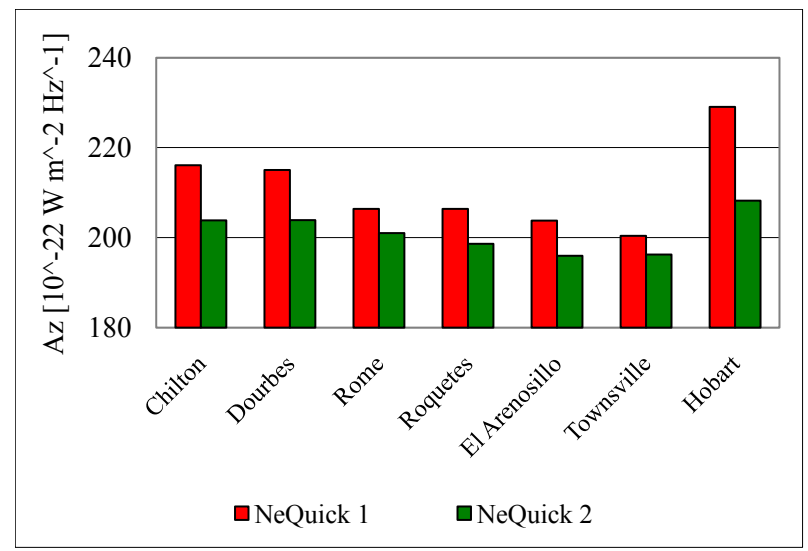

Fig. 8. Yearly $A z$ mean.

NeQuick 2 depend indeed more linearly on $A z$ than those from NeQuick 1. Consequently, in many cases, a smaller increase in $A z$ within some intermediate interval (e.g. between 140 and 240 flux units for most of the year at Dourbes) leads to the same gain in $v T E C$. The dependence of $A z$ towards latitude - increasing towards high latitudes - justifies also the representation of the global daily $A z$ for the Galileo algorithm as a second order polynomial of $\mu$.

For the Galileo SF ICA, the broadcast coefficients valid for one day will be estimated from the effective parameters of the previous day. Using the latter instead of the current day $A z$ values enables us to focus on the impact of the day-to-day variability only. On the one hand, we notice a comparable underestimation (around $8 \%$ on average) for both versions (cf. Fig. 7). On the other hand, the relative standard deviation increases up to $21 \%$ on average. The other observations detailed for sTEC data ingestion using current day $\mathrm{Az}$ are similar for all regions and versions of NeQuick.

\subsection{Ionospheric correction algorithms}

The last step of our reasoning relates to the ionospheric corrections provided to single frequency users. In the case of Galileo, we calculate NeQuick daily effective parameters at our 12 test locations from the simulated broadcast coefficients of the IOV phase (cf. Section 2.3). As in the previous subsections, we inspect yearly statistics of $v T E C$ (cf. Fig. 9) and we compare them with the latest use of previous day $A z$. We still obtain an underestimation, larger for NeQuick 1 (around 10\% for mid-latitude Europe and North America, about 16\% for Australia) except for high-latitude Europe (dropping to $5 \%$ ), and smaller for NeQuick 2 (less than 3\% for mid-latitude Europe and North America, 7\% for high-latitude Europe) except for Australia (9\%). Considering the relative standard deviation, the only noticeable increase appears 

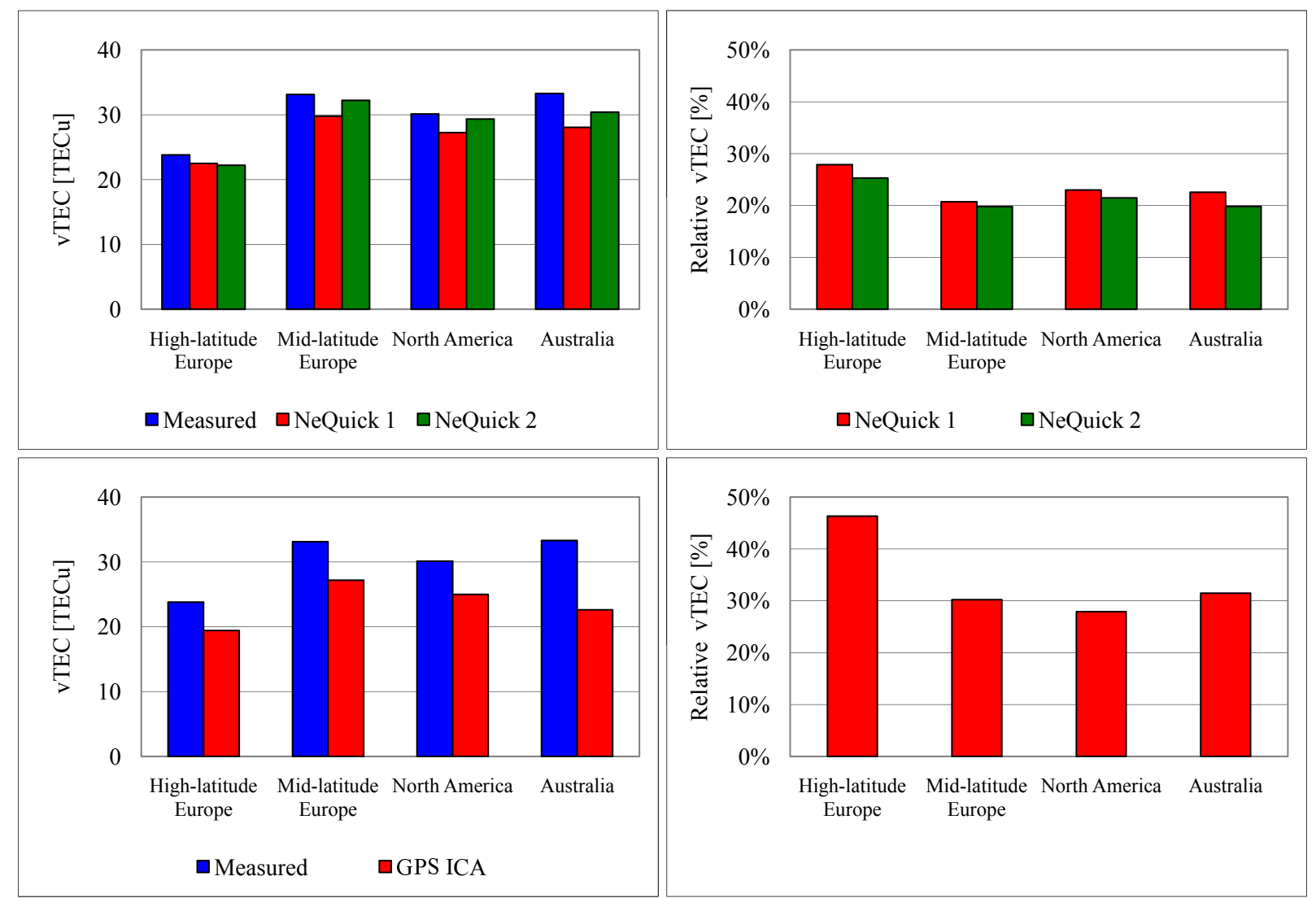

Fig. 9. Yearly $v T E C$ mean (left) and relative standard deviation (right) corresponding to the Galileo (top) and GPS (bottom) SF ICA.

for North America. Therefore the influence of the interpolation of $A z$ from the broadcast coefficients seems much smaller than the day-to-day variability.

The above-described evolution of $v T E C$ underestimation can be explained comparing, for the different regions of interest, yearly means of $A z$ involved in the Galileo ionospheric correction and local one (cf. Fig. 10; crosses for the second and corresponding points on the curves for the first). Indeed we find corresponding differences between $A z$ values for both uses of NeQuick: negative for NeQuick 1 (inducing a larger $v T E C$ bias) except for high-latitude Europe, and positive for NeQuick 2 (leading to a smaller $v T E C$ bias) except for Australia. Several statements related to $s T E C$ data ingestion effective parameters (cf. Fig. 8) still hold in this case. All interpolated $A z$ values exceed the yearly mean converted $R_{12}$. The improved topside formulation leads to smaller $A z$ variations for NeQuick 2 (smaller range of values between minimum at low latitudes and maximum at high latitudes).

Finally a comparison between Galileo and GPS ionospheric corrections is of prime interest. The GPS SF ICA also underestimates $v T E C$ (by around $18 \%$ except for Australia with about 32\%; cf. Fig. 9). However the computed biases amount between about 1.8 (mid-latitude Europe and North-America 


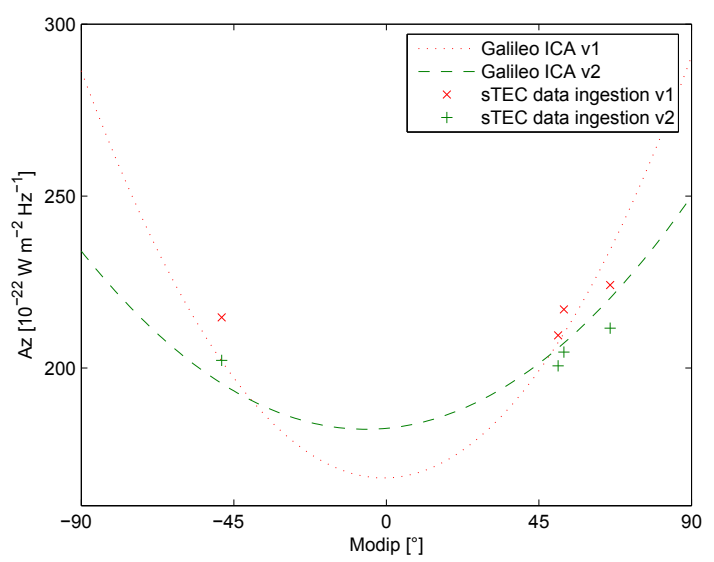

Fig. 10. Comparison between yearly $A z$ mean obtained from Galileo broadcast coefficients and $s T E C$ data ingestion.

for NeQuick 1) and around 6.5 (same regions for NeQuick 2) times those of the Galileo SF ICA. The ratio between GPS and Galileo standard deviations equals around 1.5 with a value of around $30 \%$ for this statistic in the case of the Klobuchar algorithm (except for high-latitude Europe with about 46\%). Following its design drivers (main interest in the CONUS area), it reaches its best performances in North America.

\subsection{Synthesis}

In the current section, we have been able to differentiate the performances of the different steps of the Galileo ionospheric correction for single frequency users in terms of $v T E C$. To reach this goal, we established yearly statistics for the year 2002 at 12 locations (cf. Fig. 11; mean $v T E C$ of 31 TECu).

We depicted an $8 \%$ underestimation for both versions of NeQuick in the cases involving $s T E C$ data ingestion. This value was three times larger when constraining the model with ionosonde parameters. NeQuick 2 provided better means than NeQuick 1 for cases involving ingestion (more than twice for the Galileo ICA) but worse for the first use of the model. Comparing the latter to $s T E C$ data ingestion, we observed averages decreasing by $2.5-4$. Replacing the effective parameters by their values for the previous day did not imply significant modifications. On the contrary, employing the effective ionisation level deduced from simulated broadcast coefficients lead to a different evolution for NeQuick 1 (about 20\% larger underestimation) and NeQuick 2 (about 40\% smaller). For the same situations, the GPS ICA ended up with a $20 \%$ underestimation. If performed thus better than when NeQuick was driven with ionosonde parameters but worse than procedures involving data ingestion. Considering Galileo ionospheric correction in particular, the bias 

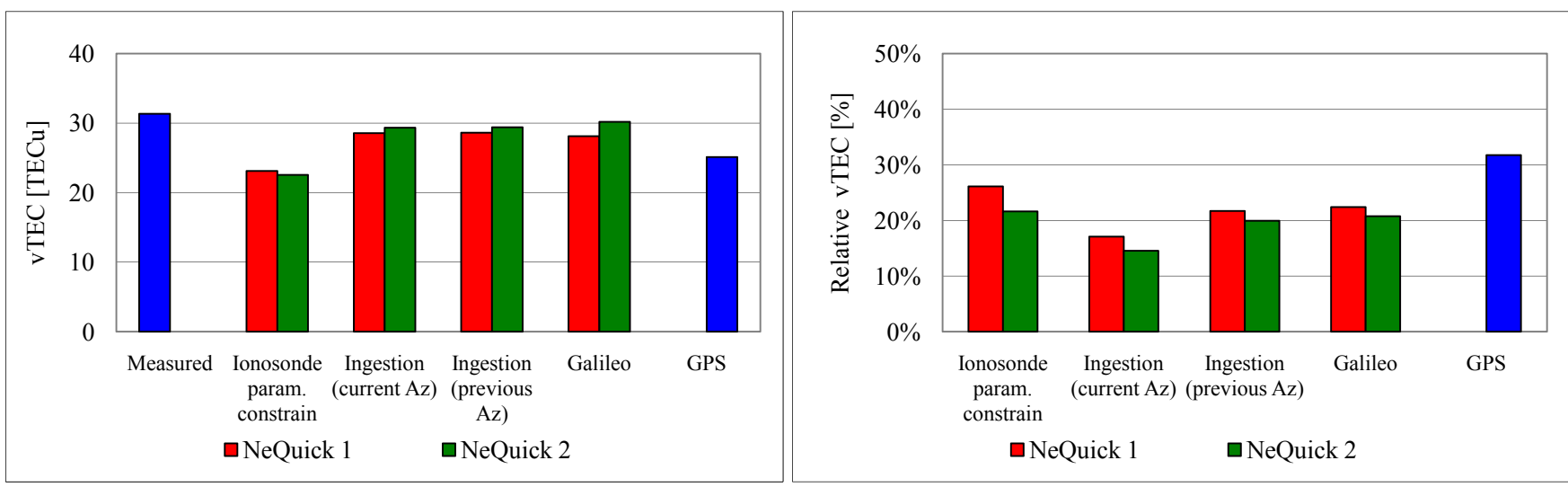

Fig. 11. Yearly $v T E C$ mean (left) and relative standard deviation (right) corresponding to analysed modelling techniques.

equalled twice and 5 times those obtained with NeQuick 1 and 2 respectively.

The second major statistic assessed consisted in the relative standard deviation of the difference between modelled and measured $v T E C$. Its values ranged from $15 \%$ (sTEC data ingestion, NeQuick 2) to $26 \%$ (ionosonde parameters constrain, NeQuick 1). We outlined better results from NeQuick 2 in all cases (around 15\% improvement for the first two techniques, less than $10 \%$ when using the previous day $A z$ and for the Galileo ICA). sTEC data ingestion presented the best figures, $34 \%$ smaller than when replacing CCIR maps by ionosonde measurements. Operating NeQuick with effective parameters of the previous day or based on broadcast coefficients instead of those of the current day raised the relative standard deviation by $27 \%$ to $43 \%$. In any case, it remained below the level of $32 \%$ exhibited by the GPS ICA. For the latter, we stated a 1.5-ratio with respect to the Galileo ionospheric correction.

\section{Conclusion and perspectives}

As a tool allowing to exploit different ionospheric data, the NeQuick model can be used in combination with GNSS sTEC data in the framework of an optimisation procedure called data ingestion. Instead of using solar flux as input, a new parameter, the "effective ionisation level" $A z$, is then computed in order to minimise the model mismodelling from a specific set of $s T E C$ data. This technique constitutes the basis of the Galileo SF ICA.

In order to understand how data ingestion accommodates the model residual errors, we first constrained NeQuick with ionosonde data to characterise its intrinsic mismodelling. We analysed statistically the difference between GPSderived vertical TEC and corresponding modelled values for a dozen stations distributed in four mid-latitude and high-latitude regions for the last solar 
maximum in 2002. We also considered the latest version of the model in order to quantify the evolution from the current ITU baseline. We found standard deviations decreasing by around $17 \%$ to reach about $22 \%$ in relative values with NeQuick 2; biases increasing by about $8 \%$ up to around $26 \%$ on average (care must be taken about GPS TEC data regarding the bias). Examining monthly statistics, we highlighted the influence of the unification of the topside shape parameter $k$ as the two former formulas corresponded with periods exhibiting opposite behaviours. We identified the region exhibiting the best results as mid-latitude Europe and the one with the worst as high-latitude Europe.

In a second step, we examined results of $s T E C$ data ingestion. Computing daily $A z$ values, we reached biases of about $8 \%$ and standard deviations of about $16 \%$. We also obtained better statistics with NeQuick 2 (decrease of $27 \%$ in bias and $15 \%$ in standard deviation). We stated that $A z$ values are much larger than the usual solar indices as they must drive TEC to accommodate residual errors. We also noted the dependence of $A z$ on latitude: increasing towards high latitudes. Running NeQuick with the previous day effective ionisation level, another common characteristic with the Galileo ionospheric correction, mainly impacted the relative standard deviation which enlarges then to about $21 \%$.

Ultimately we compared the Galileo and GPS SF ICA. For the first, the parabolic formulation of $A z$ in function of modip and the broadcast coefficients primarily induced a larger underestimation for NeQuick 1 (11\%) and a smaller one for NeQuick 2 (4\%). We explained this difference by a larger sensitivity to $A z$ variations for the second version of the model. Nevertheless we concluded to a better correction for Galileo than for GPS taking into account the $20 \%$ bias and the $32 \%$ standard deviation of the Klobuchar algorithm.

To deepen our analysis, we will consider statistics of other ionospheric parameters such as $s T E C$ or maximum electron concentrations. This will allow us to investigate the interest of different data ingestion schemes based on the NeQuick model (Buresova et al., 2009) and their applicability to GNSS applications. Another important user-oriented future research direction will relate to the ionospheric corrections performances in terms of position.

\section{Acknowledgments}

The work presented in this paper is part of B. Bidaine's PhD Thesis in progress under a F.R.S.-FNRS fellowship (Belgian National Fund for Scientific Research). B. Bidaine would like to acknowledge S. Radicella, P. Coïsson and B. Nava from ICTP in Trieste for their wise comments about NeQuick 
of which they entrusted the latest version to him; I. Blanco Alegre from INTA (El Arenosillo), D. Altadill from Observatori de l'Ebre (Roquetes), E. Van Malderen, L. Lejeune, G. Crabbé and S. Stankov from RMI (Dourbes) for providing ionosonde data and comments about them; G. Khmyrov and B. Reinisch from UMLCAR in Boston for providing access to the DIDBase (digisonde database); the UK Solar System Data Centre staff in Chilton for providing access to and maintaining ionospheric data; R. Prieto-Cerdeira and R. Orus from ESA/ESTEC for providing TEC data and comments about them; M. Lonchay from ULg for contributing to software development; A. Komjathy from JPL for fruitful discussion about data assimilation techniques.

\section{References}

Altadill, D., Boska, J., Cander, L. R., Gulyaeva, T., Reinisch, B. W., Romano, V., Krankowski, A., Bremer, J., Belehaki, A., Stanislawska, I., Jakowski, N., Scotto, C. Near Earth space plasma monitoring under COST 296. Ann. Geophys. 52 (3/4), 221-234, 2009.

Arbesser-Rastburg, B. The Galileo Single Frequency Ionospheric Correction Algorithm. Presented at the 3rd European Space Weather Week, Brussels, Belgium, 2006.

Arbesser-Rastburg, B., Jakowski, N. Effects on satellite navigation, in: Bothmer, V., Daglis, I. A. (Eds.), Space Weather - Physics and Effects. Springer Berlin Heidelberg, New York, pp. 383-402, doi:10.1007/978-3-540-34578-7_13, 2007.

Bidaine, B., Warnant, R. Towards an Improved Single-Frequency Ionospheric Correction: Focus on Mid-Latitudes, in: Proc. 4th ESA Workshop on Satellite Navigation User Equipment Technologies NAVITEC 2008 [CD-Rom]. ESA, Noordwijk, The Netherlands, 2008.

Bidaine, B., Warnant, R. Measuring Total Electron Content with GNSS: Investigation of Two Different Techniques, in: Proc. 11th International Conference on Ionospheric Radio Systems and Techniques (IRST 2009). IET, London, 201-206, doi:10.1049/cp. 2009.0063, 2009.

Bidaine, B., Warnant, R. Assessment of the NeQuick model at mid-latitudes using GNSS TEC and ionosonde data. Adv. Space Res. 45 (9), 1122-1128, doi:10.1016/j.asr.2009.10.010, 2010.

Brent, R. P. Algorithms for Minimization Without Derivatives. Prentice-Hall, Englewood Cliffs, Prentice-Hall Series in Automatic Computation, ISBN 0-13-022335-2, 1973.

Bruyninx, C., Legrand, J., Roosbeek, F. EPN Status and Network Management. Presented at the EUREF annual symposium, Florence, Italy, 2009.

Buresova, D., Nava, B., Galkin, I., Angling, M., Stankov, S. M., Coisson, P. Data ingestion and assimilation in ionospheric models. Ann. Geophys. 52 (3/4), 235-253, 2009.

Bidaine et Warnant - doi:10.1016/j.asr.2010.09.001 
Ciraolo, L., Azpilicueta, F., Brunini, C., Meza, A., Radicella, S. M. Calibration errors on experimental slant total electron content (TEC) determined with GPS. J. Geod. 81 (2), 111-120, doi:10.1007/s00190-006-0093-1, 2007.

Coïsson, P., Radicella, S. M., Leitinger, R., Nava, B. Topside electron density in IRI and NeQuick: Features and limitations. Adv. Space Res. 37 (5), 937942, doi:10.1016/j.asr.2005.09.015, 2006.

Dow, J. M., Neilan, R. E., Rizos, C. The International GNSS Service in a changing landscape of Global Navigation Satellite Systems. J. Geod. 83 (3/4), 191-198, doi:10.1007/s00190-008-0300-3, 2009.

Galkin, I. A., Khmyrov, G. M., Kozlov, A., Reinisch, B. W., Huang, X., Kitrosser, D. F. Ionosonde networking, databasing, and web serving. Radio Sci. 41 (5), RS5S33, doi:10.1029/2005RS003384, 2006.

Hernández-Pajares, M., Juan, J. M., Sanz, J., Orus, R., Garcia-Rigo, A., Feltens, J., Komjathy, A., Schaer, S. C., Krankowski, A. The IGS VTEC maps: a reliable source of ionospheric information since 1998. J. Geod. 83 (3/4), 263-275, doi:10.1007/s00190-008-0266-1, 2009.

Hofmann-Wellenhof, B., Lichtenegger, H., Wasle, E. GNSS - Global Navigation Satellite Systems. Springer, Vienna, ISBN 978-3-211-73012-6, 2008.

Klobuchar, J. A. Ionospheric Time-Delay Algorithm for Single-Frequency GPS Users. IEEE Trans. Aerosp. Electron. Syst., AES-23 (3), 325-331, 1987.

Nava, B., Radicella, S. M., Leitinger, R., Coïsson, P. A near-real-time model-assisted ionosphere electron density retrieval method. Radio Sci. 41, RS6S16, doi:10.1029/2005RS003386, 2006.

Nava, B., Coïsson, P., Radicella, S. M. A new version of the NeQuick ionosphere electron density model. J. Atmos. and Sol.-Terr. Phys. 70 (15), 18561862, doi:10.1016/j.jastp. 2008.01.015, 2008.

Orus, R., Arbesser-Rastburg, B., Prieto-Cerdeira, R., Hernandez-Pajares, M., Juan, J. M., Sanz, J. Performance of Different Ionospheric Models for Single Frequency Navigation Receivers. Presented at the 2007 Beacon Satellite Symposium, Boston, USA, 2007a.

Orus, R., Cander, Lj. R., Hernandez-Pajares, M. Testing regional vTEC maps over Europe during the 17-21 January 2005 sudden space weather event. Radio Sci. 42, RS3004, doi:10.1029/2006RS003515, 2007b.

Prieto-Cerdeira, R., Orus, R., Arbesser-Rastburg, B. Assessment of the Ionospheric Correction Algorithm for GALILEO Single Frequency Receivers, in: Proc. 3rd ESA Workshop on Satellite Navigation User Equipment Technologies NAVITEC 2006 [CD-Rom]. ESA, Noordwijk, The Netherlands, 2006.

Radicella, S. M., Leitinger, R. The evolution of the DGR approach to model electron density profiles. Adv. Space Res. 27 (1), 35-40, doi:10.1016/S0273-1177(00)00138-1, 2001.

Rawer, K. Propagation of Decameter Waves (HF-Band), in: Landmark, B. (Ed.), Meteorological and Astronomical Influences on Radio Wave Propagation. Academic Press, New York, 11, 221-250, 1963.

Snay, R. A., Soler, T. Continuously Operating Reference Station (CORS): History, Applications, and Future Enhancements. J. Surv. Eng. 134 (4), 
95-104, doi:10.1061/(ASCE) 0733-9453(2008) 134:4 (95), 2008.

Warnant, R., Pottiaux, E. The increase of the ionospheric activity as measured by GPS. Earth Planets Space 52 (11), 1055-1060, 2000.

Warnant, R., Foelsche, U., Aquino, M., Bidaine, B., Gherm, G., Hoque, M. M., Kutiev, I., Lejeune, S., Luntama, J.-P., Spits, J., Strangeways, H. J., Wautelet, G., Zernov, N., Jakowski, N. Mitigation of ionospheric effects on GNSS. Ann. Geophys. 52 (3/4), 373-390, 2009.

Wilson, B. D., Akopian, V., Komjathy, A., Pi, X., Dumett, M., Hajj, G., Wang, C., Mannucci, A. Ionospheric Data Assimilation: Techniques and Performance. Presented at the XXIXth URSI General Assembly 2008, Chicago, USA, 2008.

Bidaine et Warnant - doi:10.1016/j.asr.2010.09.001 